\title{
Assédio moral entre profissionais de enfermagem do Hospital Regional de Ceilândia/DF
}

\author{
Ítalo Vieira Barros
}

Enfermeiro, Universidade Católica de Brasilia, pós-graduado em Auditoria em Serviços de Saúde

\section{Resumo}

O objetivo deste estudo é investigar a ocorrência e as repercussōes do assédio moral entre funcionários da enfermagem de um hospital público do DF. Trata-se de um estudo exploratório e transversal, realizado no Hospital Regional da Ceilândia/DF, através da aplicação de questionário a 123 profissionais de enfermagem. Os resultados mostraram que $55(44,7 \%)$ profissionais de enfermagem já passaram por algum tipo de assédio moral no ambiente de trabalho, todos $(100 \%)$ do sexo feminino. Quanto à comparação entre a categoria profissional, os auxiliares de enfermagem apresentaram maiores índices de perseguiçáo pela chefia e de problemas para reconhecer seus direitos e deveres, e menores índices de denúncia a membros de sua equipe. Dentre os fatores relacionados ao assédio moral, o de maior ocorrência, embora predominantemente ocasionalmente, foi o constrangimento por membro da equipe. Investimento na educação, incentivo às denúncias, e à delimitação de deveres e direitos são medidas que podem levar à modificação do atual cenário.

Palavras-chave: bullying, enfermagem, trabalhadores.

\section{Abstract \\ Moral harassment among professional nursing of the Regional Hospital of Ceilândia/DF}

The objective of this study is to investigate the occurrence and impact of bullying between professional nursing in a public hospital in the Brazilian Federal District. This was an exploratory and transversal study performed at the Regional Hospital of Ceilândia/DF, Brazil, using a questionnaire to 123 nursing professionals. The results pointed out that 55 (44.7\%) nurses have experienced some type of bullying in the workplace; all (100\%) were female. A comparison between professional categories showed that the nursing assistants had higher rate of persecution by leadership and problems to recognize their rights and duties, and lower rates of reporting bullying by members of their team. Among the factors related to bullying, the most frequent, although predominantly occasionally, was the embarrassment suffered by the team member. Investment in education, encouraging complaints, and the definition of rights and duties are actions that can lead to change the current situation.

Key-words: bullying, nursing, workers. 


\section{Resumen}

\section{Acoso moral entre los profesionales de enfermería del Hospital Regional de Ceilândia/DF}

El objetivo de este estudio es investigar la ocurrencia y el impacto del acoso moral entre personal de enfermería en un hospital público en el DF. Este es un estudio exploratorio y transversal, realizado en el Hospital Regional de Ceilândia-DF, Brasil, a través de un cuestionario que se distribuyó entre 123 profesionales de enfermería. Los resultados mostraron que 55 $(44,7 \%)$ enfermeras han sufrido algún tipo de acoso en el lugar de trabajo; todas (100\%) eran mujeres. En comparación entre la categoría profesional, los auxiliares de enfermería tenían una mayor tasa de acoso por parte de los jefes y de problemas en reconocer sus derechos y deberes; además las tasas de denuncia a los miembros de su equipo eran muy bajas. Entre los factores relacionados con el acoso, el más frecuente, aunque de vez en cuando, ha sido el constreńimiento por miembro del equipo. La inversión en educación, incentivo a la denuncia, y la delimitación de derechos y deberes son medidas que pueden conducir a la modificación de la situación actual.

Palabras-clave: acoso, enfermería, trabajadores.

\section{Introdução}

A enfermagem, durante toda sua história, sempre sofreu alguma espécie de exploração. $\mathrm{O}$ mundo globalizado e o crescimento do capitalismo favorecem o aparecimento de violências relacionadas ao trabalho e, assim, torna vulnerável a relação entre empregado e empregador.

O assédio moral é a exposição dos trabalhadores a situaçóes humilhantes e constrangedoras, repetitivas e prolongadas durante a jornada de trabalho e no exercício de suas funções [1]. Tais situações são mais comuns em relaçôes hierárquicas autoritárias e assimétricas, em que predominam condutas negativas, relaçóes desumanas e aéticas de longa duração, e de um ou mais chefes dirigida a um ou mais subordinados [1]. Esse ambiente de conflitos desestabiliza a relação da vítima com o ambiente de trabalho e com a organização, podendo levar a desistência do emprego [1].

Os novos modelos de análise da violência no ambiente de trabalho, proposto pela Organização Internacional do Trabalho (OIT), demonstram que as manifestaçôes físicas e psicológicas são igualmente consideradas, dando destaque aos atos de violência considerados até o momento como "menos graves", tais como o amedrontamento, a intimidação ou o assédio psicológico no trabalho. Também a partir desta proposta, rejeita-se a ideia de que a violência no ambiente de trabalho comporte unicamente fatores pessoais e passa-se a considerá-la como resultante de uma combinação de causas relativas às pessoas, ao ambiente de trabalho e às condiçôes organizacionais e contratuais do trabalho, assim como às formas de interação entre os próprios trabalhadores, entre os clientes, e entre trabalhadores e empresários [2].

$\mathrm{O}$ assédio moral foi apontado como objeto de pesquisa, em 1996, na Suécia, pelo psicólogo do trabalho Heynz Leymann, que, por meio de um levantamento junto a vários grupos de profissionais chegou a um processo que qualificou de "psicoterror", cunhando o termo mobbing (um derivado de mob, que significa horda, bando ou plebe), devido à similaridade dessa conduta com um ataque rústico, grosseiro [3].

Esse fenômeno também pode ser descrito como "um conflito cuja ação visa à manipulação da pessoa no sentido não amigável" e que essa ação pode ser analisada através de três grupos de comportamentos: 1) um grupo de ações se desenvolve quanto à comunicação com a pessoa atacada, tendendo à interrupção da comunicação; 2) outro grupo de comportamento se assenta sobre tentativas de denegrir a reputação da pessoa atacada; 3) as açóes do terceiro grupo tendem a manipular a dignidade profissional da pessoa agredida. Somente se estas forem realizadas propositalmente, frequentemente e por muito tempo podem ser chamadas de "mobbing" [4]. Um quarto mecanismo também pode ser acrescentado: a manipulação das contrapartidas laboratoriais [5] (Quadro I). 
Quadro I - Formas de expressão do mobbing.

\begin{tabular}{ll}
\hline \multicolumn{1}{c}{ Grupos de ações } & \multicolumn{1}{c}{ Mecanismos } \\
\hline Manipulação da comunicação da vítima & Negação de informação relativa ao posto de trabalho, como as \\
& funções e responsabilidades, os métodos de trabalho: a quantidade, \\
& qualidade e prazos do trabalho a ser realizados. \\
& Comunicação hostil explícita, com críticas e ameaças públicas. \\
& Comunicação hostil implícita, como o não dirigir palavra, ou negar \\
& cumprimento. \\
\hline Manipulação da reputação da vítima & Realização de comentários injuriosos, com ridiculizações públicas, rela- \\
& tivas ao aspecto físico ou às idéias ou convicções políticas ou religiosas. \\
& Realização de críticas sobre o profissionalismo da vítima. \\
& Assédio sexual da vítima. \\
\hline Manipulação do trabalho da vítima & Aumento da sobrecarga de trabalho. \\
& Atribuições de trabalhos desnecessários, monótonos ou rotineiros. \\
& Atribuições de tarefas de qualificação inferior à da vítima. \\
& Atribuições de demandas contraditórias ou excludentes. \\
& Atribuições de demandas contrárias aos padrões morais da vítima. \\
Não atribuição de tarefas. & Negação dos meios de trabalho. \\
\hline Manipulação das contrapartidas laborais & Discriminação nos salários, nos turnos, jornada ou em outros direitos. \\
Discriminação quanto ao respeito, o tratamento ou no protocolo.
\end{tabular}

Fonte: Leymann (1996); Suárez (2002). Apud: Fonte: Guimarães e Rimoli (2006). Com adaptações.

Sendo o assédio moral uma agressão e não um conflito, há a intenção do agressor de ferir ou prejudicar a vítima, objetivando, por muitas vezes, seu controle e domínio e, para isso, usurpando a higidez psicológica do assediado. Náo se trata, portanto, de uma descarga de agressividade de um indivíduo vítima do estresse ou das condiçôes adversas no trabalho, ou da pressão que sofre no mesmo ambiente, tampouco uma perda de controle, mas sim uma vontade de dominar sua vítima [6].

Geralmente o assédio moral nasce com pouca intensidade, como algo inofensivo e falsamente irrelevante, levando a vítima a tolerar as agressóes, e a levá-las na brincadeira. Isso funciona como reforço para aumento na frequência e gravidade das agressóes. Tal situação provavelmente acontece justamente porque as vítimas temem fazer denúncias formais, com medo do "revide", que poderia vir através de demissão ou de rebaixamento de cargo; além do receio de que a denúncia torne pública a humilhação pela qual passaram, o que levaria a mais constrangimento e vergonha. Assim, o medo (de caráter mais objetivo) e a vergonha (mais subjetiva, mas com consequências devastadoras) se unem, acobertando a covardia das agressóes.

As formas de assédio moral, frequentemente identificadas no exercício da enfermagem são: humilhaçôes em público e à portas fechadas, com ameaças; depreciação da imagem profissional; boatos e rumores maldosos; cobranças absurdas por parte das chefias; delegação de tarefas que não podem ser realizada [7].

$\mathrm{O}$ assédio moral pode ser de três tipos: ascendente, quando por uma pessoa de um nível hierárquico superior é agredida por um ou vários subordinados; horizontal, quando um trabalhador é assediado por um colega do mesmo nível hierárquico; e do tipo descendente, situação mais frequente, quando a pessoa que detém o poder assedia seu subordinado com falsas acusaçóes e insultos, atingindo a esfera psicológica do trabalhador assediado, e com isso mantendo sua posição hierárquica [7].

A violência no local de trabalho, em qualquer de suas manifestaçóes, pode ter efeito devastador e de longa duração nas pessoas afetadas. Ela não se relaciona apenas a fatores pessoais e comportamentais, mas também a fatores estruturais, inclusive da própria organização do trabalho [8].

A violência se manifesta de diferentes formas e acomete diversos grupos de pessoas, razão pela qual se torna difícil sua apreensão e definição [8]. Uma medida a ser tomada para a compreensão do fenômeno violência é negar a aceitação de sentenças abstratas e aceitá-la como um fenômeno ambíguo. Além disso, é preciso um adequado preparo para o seu enfrentamento de suas manifestaçóes, questionando-a sobre as suas formas de ataque e buscando 
os métodos necessários para detê-la. No ambiente de trabalho ela se caracteriza de três formas [9]:

1) Violência externa, que é provocada por alguém que não pertence a organizaçáo, por exemplo, a violência que se tem nas ruas e que é provocada por alguém desconhecido. Neste caso, os trabalhadores de saúde têm um risco maior de serem afetados, dependendo da localização geográfica da instituição de trabalho, como periferias e locais com elevado consumo de drogas [9];

2) Violência provocada pelo cliente, que pode ser bem exemplificada pelos trabalhadores de saúde, que lidam com uma clientela muito diversificada, composta muitas vezes por pacientes psiquiátricos, delinquentes, drogados, embriagados, e familiares agressivos, especialmente em caso de óbito do parente [9];

3) Violência interna, que é aquela que ocorre entre trabalhadores de uma mesma instituição, podendo vir tanto de um funcionário hierarquicamente superior, quando de colegas de posição similar à da vítima. A violência através de assédio moral geralmente se encaixa nessa categoria [9].

A satisfação com o trabalho é um conjunto de sentimentos favoráveis que os indivíduos apresentam em relaçáo ao mesmo, e quanto maiores forem os fatores de satisfação, maior poderá ser o empenho do profissional em prestar uma assistência qualificada, refletindo um serviço de melhor qualidade [10].

$\mathrm{O}$ assédio moral consiste em um fenômeno relevante, porém, ainda pouco discutido no contexto histórico da saúde, especialmente na enfermagem. Esse é um assunto merecedor de destaque, já que pode desestruturar a vida de um indivíduo, não somente no que se refere ao seu desempenho no trabalho, mas também à sua autoestima e relaçôes sociais.

O tema é polêmico e importante para as diversas formas de trabalho existentes no mundo. De acordo com o juiz do trabalho Mauro Vasni Paroski esse tema é ainda muito novo [11], e por decorrência disto, ainda existem poucos estudos publicados no Brasil. A realização de novas pesquisas referentes ao assédio moral é necessária para que se possa mensurar a real ocorrência e impacto desse fenômeno, especialmente nas instituiçôes de saúde.

Os objetivos desta pesquisa são: investigar a ocorrência de assédio moral entre profissionais de saúde da equipe de enfermagem do Hospital Regional da Ceilândia; avaliar a frequência das formas de assé- dio moral entre a equipe de enfermagem do Hospital Regional da Ceilândia; e comparar a frequência de assédio moral entre gênero e categoria profissional.

\section{Material e métodos}

Este artigo é exploratório, de caráter transversal, com análise de dados quantitativa e qualitativa. Os dados foram tratados em banco do programa SPSS (Statistical Package for the Social Sciences) e os seus resultados relacionados em tabelas. Foi aplicado um questionário aos profissionais de enfermagem do Hospital Regional da Ceilândia/ DF. O questionário foi dividido em três sessóes principais: a primeira abrange a identificação e perfil profissional do entrevistado, com ênfase na categoria em que atua (enfermeiro, auxiliar de enfermagem ou técnico de enfermagem); a segunda, constituída de quatro tópicos, avalia a frequência de tipos de assédio moral; e a terceira, com seis tópicos, avaliar as consequências do assédio moral.

$\mathrm{Na}$ segunda sessão, os fatores relacionados ao assédio moral analisados foram: 1) perseguição pela chefia; 2) ter passado por alguma ameaça no trabalho; 3) ter sido humilhado pela chefia; e 4) ter passado por constrangimento por algum membro de sua equipe. $\mathrm{Na}$ terceira sessão, os itens avaliados foram: 1) ter problemas psicológicos por decorrência de algum assédio; 2) ter procurado ajuda por causa do trabalho; 3) ter tomado remédio controlado ou para manter o controle; 4) ter sentimento de vingança; 5) já ter denunciado alguém de sua equipe; e 6 ) ter problemas para reconhecer seus direitos e deveres.

Em relação à frequência analisada na segunda e terceira sessão, foram consideradas as frequências de nunca, ocasional e frequente. Considerou-se como ocasional quando o intervalo médio entre as agressôes foi maior que três meses entre as agressóes, e como frequente quando o intervalo médio foi menor que três meses. A frequência de nunca foi omitida das tabelas (anexo 1). No questionário consta ainda um espaço opcional para depoimentos, onde puderam ser relatadas situaçóes vivenciadas de assédio moral.

Foi questionada $19,61 \%$ da equipe de enfermagem lotada na regional de Ceilândia/DF. Foram incluídos profissionais de enfermagem (auxiliares de enfermagem, técnicos de enfermagem e enfermeiros) que atuam na regional da Ceilândia/DF e que aceitaram participar do estudo proposto. Foram excluídos os profissionais que não aceitaram participar da pesquisa e os que náo pertencem à área da 
enfermagem. $\mathrm{O}$ projeto foi submetido ao Comitê de Ética em Pesquisa da Fundação de Ensino e Pesquisa em Ciências da Saúde - SES (Secretaria de Estado de Saúde) e aprovado sob o número 177/10.

\section{Resultados}

Atualmente, a equipe de enfermagem do Hospital Regional da Ceilândia conta com 506 auxiliares de enfermagem e 121 enfermeiros, não existindo no quadro de funcionários o cargo de técnico de enfermagem.

A pesquisa envolveu 123 profissionais de enfermagem, o que corresponde a $19,61 \%$ do contingente do serviço. Destes, 99 (80,5\%) atuam como auxiliares de enfermagem e 24 (19,5\%) como enfermeiros. Em relação ao sexo, foram entrevistados 9 homens $(7,3 \%)$ e 114 mulheres $(92,7 \%)$. Os resultados apontam que $55(44,7 \%)$ profissionais de enfermagem já passaram por algum tipo de assédio moral no ambiente de trabalho, todos (100\%) do sexo feminino. A Tabela I apresenta a relação entre o gênero e a ocorrência de assédio moral.

Tabela I - Relação entre gênero e ocorrência de assédio moral dos profissionais de enfermagem ( $n=123$ ) do Hospital Regional da Ceilândia, DF, Brasil, 2011.

\begin{tabular}{lccc}
\hline & $\begin{array}{c}\text { Sofreram } \\
\text { Assédio }\end{array}$ & $\begin{array}{c}\text { Não } \\
\text { Sofreram } \\
\text { Assédio }\end{array}$ & Total \\
\hline Sexo Feminino & $55(48,2 \%)$ & $59(51,8 \%)$ & $114(100 \%)$ \\
Sexo Masculino & $0(0 \%)$ & $9(100 \%)$ & $09(100 \%)$ \\
Total & $55(44,7 \%)$ & $68(55,3 \%)$ & $123(100 \%)$ \\
\hline
\end{tabular}

Fonte: Hospital Regional da Ceilândia-DF (2011).

Os profissionais de enfermagem encontram-se especialmente expostos à violência no ambiente de trabalho, sobretudo em serviços hospitalares [12]. Entretanto, pouco se discute sobre as diferentes pre- valências entre os enfermeiros, técnicos e auxiliares de enfermagem. Neste estudo, o assédio moral se mostrou mais frequente entre profissionais auxiliares de enfermagem do que entre os enfermeiros, lembrando que a categoria de técnicos de enfermagem náo pode ser analisada pela inexistência desse cargo no serviço estudado. Dos 55 profissionais que sofreram assédio, 87,3\% (48) são auxiliares de enfermagem, enquanto apenas $12,7 \%$ (7) dos enfermeiros foram vítimas de assédio moral (Tabela II).

Tabela II - Relação entre cargo e ocorrência de assédio moral dos profissionais de enfermagem $(n=123$ ) do Hospital Regional da Ceilândia, DF, Brasil, 2011.

\begin{tabular}{lcl}
\hline & $\begin{array}{c}\text { Sofreram As- } \\
\text { sédio }\end{array}$ & $\begin{array}{c}\text { Não Sofreram } \\
\text { assédio }\end{array}$ \\
\hline $\begin{array}{l}\text { Enfermeiros } \\
\text { Auxiliares de En- }\end{array}$ & $48(12,7 \%)$ & $17(25 \%)$ \\
fermagem & $55(100 \%)$ & $68(100 \%)$ \\
Total & $51(75 \%)$ \\
\hline
\end{tabular}

Fonte: Hospital Regional da Ceilândia-DF (2011).

Nesta pesquisa foi verificado que os auxiliares de enfermagem são vítimas de assédio moral com maior frequência que os enfermeiros. A perseguição pela chefia, ameaça no local do trabalho e humilhaçáo pela chefia ocorrem com maior frequência entre auxiliares de enfermagem. O cargo de enfermeiro obteve maiores valores percentuais apenas em relação ao constrangimento por algum membro da equipe (29,16\%), mesmo assim, com uma diferença menor que $4 \%$. A Tabela III apresenta quatro fatores relacionados ao assédio moral e a frequência de cada um por categoria profissional.

Ainda em relação à Tabela III, merece destaque que os entrevistados consideram que os assédios ocorrem mais ocasionalmente do que frequentemente. Entre os que ocorrem com frequência ocasional, destacam-se o constrangimento por algum membro de sua equipe, com $22(22,22 \%)$ casos, seguido de ameaça no

Tabela III - Distribuição dos tipos de assédios envolvendo profissionais de enfermagem ( $\mathrm{n}=123$ ) do Hospital Regional da Ceilândia, DF, Brasil, 2011.

\begin{tabular}{lcccccc}
\hline \multirow{2}{*}{ Tipos de Assédios Relatados } & \multicolumn{5}{c}{ Categoria Profissional } \\
\cline { 2 - 6 } & \multicolumn{2}{c}{ Enfermeiros $(\mathrm{n}=24)$} & Aux. de Enfermagem $(\mathrm{n}=99)$ & Total $(\mathrm{n}=123)$ \\
\cline { 2 - 7 } & Ocasional & Frequente & Ocasional & Frequente & Ocasional & Frequente \\
\hline Perseguido pela chefia & 0 & 0 & $14(14,14 \%)$ & $6(6,06 \%)$ & $14(11,38 \%)$ & $6(4,87 \%)$ \\
\hline Ameaça no local de traba- & $2(8,33 \%)$ & $1(4,16 \%)$ & $18(18,18 \%)$ & $5(5,05 \%)$ & $20(16,26 \%)$ & $6(4,87 \%)$ \\
\hline lho & $1(4,16 \%)$ & 0 & $11(11,11 \%)$ & $5(5,05 \%)$ & $12(9,75 \%)$ & $5(4,06 \%)$ \\
\hline Humilhado pela chefia & $7(29,16 \%)$ & 0 & $22(22,22 \%)$ & $3(3,03 \%)$ & $29(23,57 \%)$ & $3(2,43 \%)$ \\
\hline $\begin{array}{l}\text { Constrangimento por algum } \\
\text { membro de sua equipe }\end{array}$ & & & & &
\end{tabular}

Fonte: Hospital Regional da Ceilândia-DF (2011). 
local de trabalho, com $18(18,18 \%)$ casos. Na categoria enfermeiro encontramos 7 (29,16\%) entrevistados que já passaram por algum constrangimento por membro de sua equipe, também ocasionalmente.

Na Tabela IV estão enumeradas as consequências sofridas pelos entrevistados após sofrerem assédio, nela destacamos que $16(16,16 \%)$ dos auxiliares de enfermagem tiveram problemas para reconhecer seus direitos e deveres, e $6(25,0 \%)$ enfermeiros já tiveram que denunciar alguém de sua equipe.

Quanto à questão de sofrimento de assédio moral e desejo de relatar o ocorrido, apenas três entrevistados optaram por expor depoimentos sobre assédio moral, os quais estão citados a seguir:

"O chefe queria transferir eu e os meus colegas com mais de 20 anos de função, querendo apenas os novatos para lapidá-los." (Entrevistado no. 6)

"Passei por assédio moral no meu primeiro emprego em um hospital particular do DF, onde a enfermeira-chefe me impugnou por um fato onde ela me julgou estar errada e disse que não queria ouvir minha defesa, que eu tinha apenas que escutar ou teria que me demitir se acontecesse novamente." (Entrevistado no12)

"Fui chamado atenção por um determinado fato na frente de outras colegas e até mesmo na presença de pacientes." (Entrevistado n²1)

\section{Discussão}

O assédio moral é entendido como uma conduta abusiva, intencional, frequente e repetida, que tem como objetivo diminuir, humilhar, vexar, constranger, desqualificar e demolir psicamente um indivíduo ou grupo, degradando suas condiçóes de trabalho, atingindo a sua dignidade e comprometendo a sua integridade pessoal e profissional [13]. Assim, ele traz sofrimento repetitivo e/ou sistemático, manifestando sua intenção de prejudicar ou mesmo de destruir.

$\mathrm{O}$ assédio moral não é uma novidade, podendo-se inferir que tem a mesma idade da definição de trabalho. Situações constrangedoras e humilhantes são cada vez mais comuns nos ambientes de trabalho. Considerando a atual sociedade brasileira nos moldes da escravocracia, pensa-se que a humilhação no trabalho, ou o assédio moral, sempre existiu nas mais diferentes formas ao longo da história. A humilhação está embasada no próprio sistema macroeconômico, que em seu processo disciplinar, favorece o aparecimento dessa forma de violência, em que o superior hierárquico detém poder sobre seu subordinado [13].

Como se pode entender, o assédio moral tem predominância de condutas negativas, não se tratando de uma síndrome, mas de um aspecto de destruição que envolve o bem estar, o medo e a autoestima do trabalhador, levando a vítima a desenvolver problemas de saúde ou a perder o emprego. É certo que este é o ponto de partida do evento quando ele já se tornou uma causa médica ou jurídica, ou seja, a doença e o

Tabela IV - Distribuição das consequências sofridas pelos profissionais de enfermagem ( $n=123)$ do Hospital Regional da Ceilândia, DF, Brasil, 2011.

\begin{tabular}{|c|c|c|c|c|c|c|}
\hline \multirow{3}{*}{$\begin{array}{l}\text { Consequência do Assédio } \\
\text { Sofrido }\end{array}$} & \multicolumn{6}{|c|}{ Categoria Profissional } \\
\hline & \multirow{2}{*}{\multicolumn{2}{|c|}{$\begin{array}{l}\text { Enfermeiros } \\
\quad(n=24)\end{array}$}} & \multirow{2}{*}{\multicolumn{2}{|c|}{$\begin{array}{l}\text { Auxiliares de Enfermagem } \\
\qquad(\mathrm{n}=99)\end{array}$}} & \multirow{2}{*}{\multicolumn{2}{|c|}{$\begin{array}{c}\text { Total } \\
(\mathrm{n}=123) \\
\end{array}$}} \\
\hline & & & & & & $\begin{array}{l}\text { 123) } \\
\text { Frequente }\end{array}$ \\
\hline Problemas psicológicos & & & & & & \\
\hline $\begin{array}{l}\text { por decorrência de algum } \\
\text { assédio }\end{array}$ & 0 & 0 & $8(8,08 \%)$ & $3(3,03 \%)$ & $8(6,50 \%)$ & $3(2,43 \%)$ \\
\hline $\begin{array}{l}\text { Procurou ajuda por causa } \\
\text { do assédio no trabalho }\end{array}$ & $2(8,33 \%)$ & 0 & $8(8,08 \%)$ & $4(4,04 \%)$ & $10(8,13 \%)$ & $4(3,25 \%)$ \\
\hline $\begin{array}{l}\text { Tomou algum fármaco } \\
\text { controlado ou para manter } \\
\text { o controle }\end{array}$ & 0 & 0 & $10(10,10 \%)$ & $5(5,05 \%)$ & $10(8,13 \%)$ & $5(4,06 \%)$ \\
\hline Sentimento de vingança & 0 & 0 & $6(6,06 \%)$ & $2(2,02 \%)$ & $6(4,87 \%)$ & $2(1,62 \%)$ \\
\hline $\begin{array}{l}\text { Denunciar alguém de sua } \\
\text { equipe }\end{array}$ & $6(25,0 \%)$ & 0 & $5(5,05 \%)$ & $1(1,01 \%)$ & $11(8,94 \%)$ & $1(0,81 \%)$ \\
\hline $\begin{array}{l}\text { Problemas para reconhecer } \\
\text { seus direitos e deveres }\end{array}$ & 0 & 0 & $12(12,12 \%)$ & $4(4,04 \%)$ & $12(9,75 \%)$ & $4(3,25 \%)$ \\
\hline
\end{tabular}

Fonte: Hospital Regional da Ceilândia-DF (2011). 
desemprego são resultantes diretos no nível individual [13]. Muitas vezes essa violência é encarada como normal pelo trabalhador, isso porque as condutas ofensivas tornam-se rotineiras e até mesmo toleráveis.

Os resultados obtidos através deste estudo permitem que se infira que o sexo feminino e a categoria de auxiliar de enfermagem são fatores de risco ainda maiores para a ocorrência de assédio moral do que apenas o fato de compartilharem a área da enfermagem, fator este já sabidamente predisponente à agressão moral.

$\mathrm{O}$ fato encontrado de que as agressóes ocorreram principalmente (e neste caso, totalmente) entre mulheres são compatíveis com a maioria dos artigos referentes ao tema. A atuação de forma direta e continua com pacientes e a composição majoritária de mulheres na enfermagem pode contribuir para o maior risco de agressão [12].

A ocorrência de assédio moral foi mais frequente entre auxiliares de enfermagem do que nos demais cargos na área de enfermagem. Outro estudo também fez comparações entre os diferentes cargos na área de saúde, entretanto seus resultados não obtiveram diferença estatística entre essas variáveis com relaçáo à enfermagem [14]. Pode-se supor que esse fato ocorra devido ao menor tempo de formaçáo necessária para tal cargo, menores salários e alta carga horária, entretanto, novos estudos, com uma amostra maior, são necessários para ratificar esse achado e levantar novas hipóteses.

\section{Conclusão}

A frequência encontrada do assédio moral foi de $44,7 \%$. Dentre os fatores relacionados ao assédio moral, o de maior ocorrência, embora ocasionalmente, foi o constrangimento por membro da equipe. Em relação à comparação de gênero, $100 \%$ dos agredidos moralmente são do sexo feminino. Quanto ao cargo ocupado na área de enfermagem, os auxiliares de enfermagem se mostraram mais susceptíveis ao assédio moral.

Os resultados obtidos corroboram o que já é descrito na literatura atual e pregressa, exceto quanto a maior prevalência de assédio moral entre os auxiliares de enfermagem do que entre os enfermeiros. $\mathrm{O}$ assédio moral continua presente nas instituiçóes de saúde e faz vítimas física e psiquicamente.

Medidas devem ser tomadas para mudar o atual cenário. Deve-se educar o profissional a não se intimidar com ameaças e denunciar os seus agres- sores, bem como deixar clara a delimitação entre os deveres de cada compartimento da enfermagem e o direito de exercer com tranquilidade sua profissão.

Novos estudos, com amostras maiores e de maior duração, poderão trazer novas elucidaçóes sobre a frequência e consequência do assédio moral, bem como o resultado obtido quando medidas preventivas e repressivas são adotadas.

\section{Agradecimentos}

Agradeço a todos meus colegas de graduação que me apoiaram durante toda trajetória deste estudo, a Professora Doutora Maria Liz, que ajudou na triagem desse trabalho e a minha esposa que quando possível ficava ao meu lado dando apoio durante esse trajeto de formulação deste artigo.

\section{Referências}

1. Barreto MMS. Violência, saúde, trabalho: uma jornada de humilhaçóes. 1a ed. Sáo Paulo: EDUC; 2000.

2. Guimaraes LAM, Rimoli AO. "Mobbing" (assédio psicológico) no trabalho: uma síndrome psicossocial multidimensional. Rev Psic Teor e Pesq 2006;22(2):183-91.

3. Heloani JRN. Assédio moral: um ensaio sobre a expropriação da dignidade no trabalho. RAE Electron 2004;3(1):0-0.

4. Leymann $\mathrm{H}$. The content and development of mobbing at work. European Journal of Work and Organisational Psychology 1996;5(2):165-84.

5. Suarez OA. La violencia psicológica en el lugar de trabajo en el marco de la Unión Europea. Lan Har Remanak 2002;7:279-96.

6. Akl RS, Akl FAB. O assédio moral no ambiente de trabalho: conceito e características. Uberaba: Boletim Jurídico; 2003.

7. Dias HHZR. Desconstruindo o mito: o assédio moral ou violência moral [internet]. Porto Alegre: Sindicato dos trabalhadores do judiciário federal do RS; 2005.

8. Costa ALRC, Marziale MHP. Relação tempo-violência no trabalho de enfermagem em Emergência e Urgência. Rev Bras Enferm 2006;59(3):337-343.

9. Contrera-Moreno L, Contrera-Moreno MI. Violência no trabalho em enfermagem: um novo risco ocupacional. Rev Bras Enferm 2004;57(6):746-49.

10. Nunes CM, Tronchin DMR, Melleiro MM, Kurcgant P. Satisfação e insatisfação no trabalho na percepção de enfermeiros de um hospital universitário. Rev Eletr Enf 2010;12(2):252-7.

11. Paroski MV. Assédio moral no trabalho [internet]. Teresina, Jus Navigandi; 2006 out 10 [citado 2010 Abr 05]. Disponível em: URL: http://jus.com.br/revista/ texto/9021/assedio-moral-no-trabalho.

12. Oliveira AR, D’Oliveira AFPL. Violência de gênero contra trabalhadoras de enfermagem em hospital geral de São Paulo. Rev Saúde Pública 2008;42(5):868-76.

13. Freitas ME. Quem paga a conta do assédio moral no trabalho? RAE Electron SP 2007; 6(1).

14. Cezar ES, Marziale MHP. Problemas de violência ocupacional em um serviço de urgência hospitalar da Cidade de Londrina, Paraná, Brasil. Cad Saúde Pública 2006;22(1):217-21. 